WZB

ISSN Impresso: 1806-6356 ISSN Eletrônico: 2317-2983

http://dx.doi.org/10.12819/2022.19.1.3

\title{
Práticas de Gestão da Produção do Produto Escola de Samba: O Show Turístico do Carnaval Carioca
}

Production Management Practices Escola de Samba: The Carnival Carioca Turistic Show

Maria Cristina Angélico Mendonça

Doutora em Gestão Agroindustrial pela Universidade de São Carlos

Professora na Universidade Federal de Lavras E-mail: mariacam@ufla.br

Brenda Julie Laurindo Machado Graduanda em Administração pela Universidade Federal de Lavras E-mail: brenda.machado@estudante.ufla.br

Maria Gabriela Mendonça Peixoto Doutora em Engenharia de Produção pela Escola de Engenharia de São Carlos Professora na Universidade Federal de Viçosa, Campus Rio Paranaíba E-mail:mgabriela@ufv.br

Endereço: Maria Cristina Angélico Mendonça

Universidade Federal de Lavras - UFLA; Departamento de Gestão Agroindustrial, Caixa-postal: 3037, Cep 37200-900 - Lavras - Minas Gerais. Brasil.

Endereço: Brenda Julie Laurindo Machado Universidade Federal de Lavras - UFLA; Departamento de Gestão Agroindustrial, Caixa-postal: 3037, Cep 37200-900 - Lavras - Minas Gerais. Brasil.

Endereço: Maria Gabriela Mendonça Peixoto Universidade Federal de Lavras - UFLA; Departamento de Gestão Agroindustrial, Caixa-postal: 3037, Cep 37200-900 - Lavras - Minas Gerais. Brasil.
Editor-Chefe: Dr. Tonny Kerley de Alencar Rodrigues

Artigo recebido em 28/07/2021. Última versão recebida em 11/08/2021. Aprovado em 12/08/2021.

Avaliado pelo sistema Triple Review: a) Desk Review pelo Editor-Chefe; e b) Double Blind Review (avaliação cega por dois avaliadores da área).

Revisão: Gramatical, Normativa e de Formatação 


\title{
RESUMO
}

Como as escolas de samba, as empresas têm buscado, nos seus sistemas de gestão, encontrar uma fórmula para produzir um produto para encantar e satisfazer os clientes. Por essa razão, com base em reflexões oriundas da realização de um projeto de pesquisa, financiada pela Fundação de Amparo à Pesquisa de Minas Gerais, FAPEMIG, elaborou-se este artigo com o seguinte objetivo: conhecer as práticas de gestão aplicadas no desenvolvimento do produto Escola de Samba do grupo especial do Rio de Janeiro. Especificamente identificar as práticas de gestão utilizadas na concepção e definição do produto; na definição das atividades, no cronograma e nos recursos necessários para a realização do projeto; na gestão que mantém a comunicação e o fluxo de informações de forma contínua entre os envolvidos e verificar se há alinhamento, integração nas decisões e confiança. Para a realização do projeto de pesquisa, trabalhou-se, em relação aos aspectos metodológicos, a pesquisa qualitativa com o propósito exploratório. $\mathrm{O}$ instrumento de coleta de dados usado foi o roteiro de entrevistas. As análises seguiram os pressupostos da análise de conteúdo. Pelos resultados, conheceram-se as práticas de gestão aplicadas no desenvolvimento do produto Escola e Samba, "Desfile", do grupo especial do Rio de Janeiro, permeando entre as quatro áreas pilares da Administração, marketing, produção, gestão de pessoas e financeira, com uma comunicação, fluxo de informações e troca de conhecimento acontecendo, continuamente de modo informal, por meio de redes sociais. Diante disso, pode-se afirmar que há indicativos de alinhamento, integração nas decisões e confiança.

Palavras-chave: Projeto de Desenvolvimento do Produto. Gestão. Escola de samba.

\begin{abstract}
As inschools of samba, companies have sought, in their management systems, to find a formula to produce a product to delight and satisfy customers. As a result, based on reflections arising from the realization of a research project funded by the Minas Gerais Research Funding Foundation, FAPEMIG, this paper was prepared with the following objective: to know the management practices applied in the development of the Schoolof Samba product, from the Rio de Janeiro special group. Specifically, identify the management practices used in the design and definition of the product; in the activities definition, schedule and resources needed to carry out the project; in the management that maintains communication and the information flow continuously between those involved and check for alignment, integration in decisions and trust. In order to carry out the research project, qualitative research with an exploratory purpose was used, in relation to methodological aspects. The data collection instrument used was the interview script. The analyzes followed the assumptions of content analysis. The results revealed the management practices applied in the development of the School of Samba product, "Desfile", of the Rio de Janeiro special group, permeating between the four pillar areas of Administration, marketing, production, people management and finance, with a communication, information flow and knowledge exchange taking place continuously, in an informal way through social networks. Therefore, it can be said that there are indications of alignment, integration in decisions and trust.
\end{abstract}

Keywords: Product Development Project. Management. Escola de Samba. 


\section{INTRODUÇÃO}

No Brasil, o carnaval se faz muito presente e atrai turistas do mundo todo. Segundo Balaciano (2020), o Carnaval de 2019 do Rio de Janeiro impactou R \$ 3,8 bilhões na economia, tendo um movimento de turista com mais de um milhão e meio e, na rede hoteleira, a ocupação correspondeu a mais de 90\%. Foram criados, em 2018, mais de 70 mil postos de trabalho, que geraram uma arrecadação de impostos de R $\$ 179$ milhões, sendo R \$ 77 milhões de ISS para o Rio de Janeiro.

$\mathrm{Na}$ estimativa feita pela Associação Brasileira das Empresas de Serviços Terceirizados e Trabalho Temporário, em 2013, as festas de carnaval realizadas, em todo o país, geraram 250 mil empregos temporários. No referido ano, essa cadeia produtiva respondeu por 3,7\% do Produto Interno Bruto (PIB). Em 2014, 6,6 milhões de turistas foram atraídos e R $\$$,1 bilhões foram acrescidos à economia do país, o que representou um movimento entre $6 \%$ e $7 \%$ maior que no ano anterior. Foi constatado, dias após o carnaval de 2015, que apenas os viajantes brasileiros movimentaram R \$ 6,6 bilhões no período (BRAGA, 2015).

Em 2019, o levantamento anual do Ministério do Turismo mostrou que o carnaval injetou $\mathrm{R} \$ 5,4$ bilhões na economia, sendo o maior impacto econômico comparado aos cinco principais destinos de carnavais do Brasil (BRASIL, 2019). Pode-se afirmar que o carnaval é um empreendimento que gera renda a todos os envolvidos, durante o ano todo e nos dias dos desfiles de carnaval. O setor mais impactado é o turismo, uma vez que a demanda pelos serviços dos estabelecimentos comerciais, redes de hotéis, restaurantes e quiosques é alta.

As escolas de samba realizam suas atividades de preparação para o carnaval durante o ano inteiro, gerando renda, empregos, oportunidades de inclusão social, estímulo à prática do voluntariado, além de contribuir para o ensino-aprendizagem nos diversos segmentos das artes como plásticas, cênicas e musicais. Elas são organizações culturais sem fins lucrativos, cuja principal atividade é a realização do desfile durante o Carnaval (FERNANDES, 2009).

Pontes (2012) afirma que uma escola de samba é uma grande fábrica que produz emoções, por meio de uma estrutura complexa, que se parece uma linha de produção, mas com o diferencial de ter uma gama de profissionais altamente motivados, criativos e com espírito de equipe. É uma obra de produção coletiva que reúne vários profissionais com diversas habilidades e competências distintas que buscam um mesmo objetivo (JOHANN, 1996). 
Silva (2013) reforça afirmando que as escolas de samba conseguem colaboradores que muitas empresas desejam, tais como profissionais competentes e altamente motivados, com criatividade, espírito de equipe, líderes comprometidos com os desafios e resultados. Sua administração reúne funções participativas, interdependentes e integradas. Como as escolas de samba, as empresas têm buscado, nos seus sistemas de gestão, encontrar uma fórmula para produzir um produto para encantar e satisfazer os clientes. A área de administração da produção e operações é a área envolvida na elaboração e produção de um produto ou serviço, mas não atua isoladamente. Na sua gestão, deve haver o envolvimento de profissionais das demais áreas de Administração, como marketing, finanças, gestão de pessoas e seus desdobramentos. Ao projetar um produto, há a necessidade de uma integração, sincronização e alinhamento com as demais áreas de gestão da empresa.

Em virtude disso, com base em reflexões oriundas da realização de um projeto de pesquisa financiado pela Fundação de Amparo à Pesquisa de Minas Gerais, FAPEMIG, elaborou-se este artigo sobre a gestão da produção do produto escola de samba carioca. A questão norteadora foi a seguinte: quais são as práticas de gestão aplicadas no desenvolvimento desse grande espetáculo que é o Desfile do Produto Escola de Samba? O objetivo foi conhecer as práticas de gestão aplicadas no desenvolvimento do produto Escola de Samba do grupo especial do Rio de Janeiro. Especificamente identificar as práticas de gestão utilizadas na concepção e definição do produto; identificar as práticas de gestão que definiram as atividades, o cronograma e os recursos necessários para a realização do projeto; identificar as práticas de gestão que mantiveram a comunicação e o fluxo de informações de forma contínua entre os envolvidos e verificar se há alinhamento, integração nas decisões e confiança.

Para a realização do projeto de pesquisa, trabalhou-se, em relação aos aspectos metodológicos, a pesquisa do tipo qualitativa com o propósito exploratório e o objeto a Grêmio Recreativo Escola de Samba vencedora, em 2019, do grupo especial dos carnavais do Rio de Janeiro. O instrumento de coleta de dados usado foi o roteiro de entrevistas, as quais foram aplicadas aos profissionais envolvidos na produção dos desfiles por meio de videoconferências. As análises foram feitas baseadas nos pressupostos da análise de conteúdo (BARDIN, 2001; BERTO; NAKANO, 1998; TRIVINÕS, 1987). 


\section{REFERENCIAL TEÓRICAS}

Estão reunidos, a seguir, os aspectos relacionados às teorias que serviram de base para as análises dos dados coletados e, assim, responder à questão da pesquisa. Estão reunidas informações sobre Desenvolvimento de Projeto do Produto, Processo e práticas de gestão aplicadas ao desenvolvimento do produto.

\subsection{Desenvolvimento de Projeto do Produto e Processo}

De acordo com Clark e Fujimoto (1991), o desenvolvimento de produtos envolve um processo, a partir do qual a organização transforma oportunidades de mercado e suas possibilidades técnicas em informações para a fabricação de um produto comercial. Já Rozenfeld et al. (2006) definem o processo de desenvolvimento de produto como um conjunto de atividades que, quanto às necessidades do mercado, das possibilidades e restrições tecnológicas, buscam chegar às especificações de projeto de um produto e seu processo de produção, para que a manufatura seja capaz de produzi-lo.

De acordo com Clark e Fujimoto (1991), no início dos anos 90, já era possível identificar empresas com capacidade efetiva para desenvolver produtos. Por outro lado, outras se defrontavam com elevados custos alcançados, demora no lançamento, fraco desempenho, problemas de qualidade ou até mesmo com a falta de mercado para o produto desenvolvido. Nesse cenário, ao longo dos anos, algumas mudanças nos negócios impactaram a forma de praticar e gerenciar o PDP: os níveis elevados de concorrência (BAXTER, 1998; ROZENFELD et al., 2006), rápida introdução de produtos no mercado e o ciclo de vida mais curto dos produtos.

Diante desse cenário, o planejamento do produto inclui, segundo Baxter (1998): identificação de uma oportunidade, pesquisa de marketing, análise dos produtos concorrentes, proposta do novo produto, elaboração da especificação da oportunidade e a especificação do projeto. Barczak et al. (2009) argumentam que, em termos dos aspectos da gestão do PDP, que diferenciam "o melhor do resto", os resultados indicam que as melhores empresas usam diferentes tipos de métodos e técnicas para apoiar o processo de desenvolvimento do produto.

Clausing (1994) afirma que a diferença entre o êxito e o fracasso tem origem na identificação das necessidades do cliente em relação ao produto, na viabilidade de conceitos consistentes, na viabilidade de execução do projeto, na robustez da função qualidade, na 
economia de produção, no sucesso da integração, na eficácia do reaproveitamento e no impacto estratégico.

Rotondaro, Miguel e Gomes (2010) destacam que é de fundamental importância preparar um projeto detalhado e Scalice e Neumann (2015, p. 141) indicam que o objetivo do projeto de processos produtivos é assegurar que o desempenho do projeto seja adequado ao que se está tentando alcançar.

Para muitas empresas, o investimento em esforços nessa área é fator crucial para que continuem atuando no mercado. As empresas que apostam numa estratégia de inovação, por meio do desenvolvimento de novos produtos, procuram o sucesso no mercado, uma utilização otimizada de recursos e a renovação da organização. Trata-se, então, de um processo de negócio cada vez mais decisivo que, segundo Rozenfeld et al. (2006), vem se tornando vantagem competitiva para as empresas.

Assim, Gobe et al. (2004) corroboram afirmando que a gerência de produtos se faz de suma importância, dado o contexto de acirramento da competitividade empresarial e o aumento da diversidade dos produtos ofertados ao mercado. $\mathrm{O}$ desempenho do processo depende de um modelo e das práticas de gestão, que exigem das empresas um esforço e o envolvimento das áreas funcionais de Administração, pois o processo de desenvolvimento de um produto não é uma atividade rotineira e, sim, uma atividade que envolve muitas e variadas informações, segundo Resenfeld et al. (2006). Projeto de produto é um processo que descreve as etapas no projeto de desenvolvimento do produto, para a sua introdução no mercado e mostra o ciclo de vida do produto, desde o projeto até sua evolução de vendas, além dos recursos gerenciais e técnicos no processo de desenvolvimento de um projeto. Para que os projetos dos produtos sejam efetivos, deve haver uma ligação entre o que a operação está tentando alcançar e os objetivos de desempenho de seus processos (SCALICE; NEUMANN, 2015).

No desenvolvimento e execução do projeto do produto e processo e, para traçar estratégias diferenciadas, é necessário o envolvimento não só da empresa, mas também de todos os agentes incluindo fornecedores, clientes, parceiros e outros, que representam um papel na atividade da empresa. Os autores Bidault, Desprese e Butler (1996) demonstram que o relacionamento com os fornecedores e a sua participação, durante o processo, faz com que a empresa tenha foco nos custos, já nas primeiras etapas do projeto, pois são evitados muitos custos de manufatura, pela execução de projetos mais adaptados à realidade da produção.

A evolução das abordagens ao Processo de Desenvolvimento de Produto (PDP) está relacionada com o desenvolvimento de novos sistemas de gerenciamento e engenharia nas 
empresas de manufatura, no decorrer do tempo. Envolve também um planejamento estratégico e o acompanhamento do processo de produção (STARK, 2006; WOMACK; JONES; ROOS, 1992). De acordo com Santos e Forcellini (2005) e Santos, Forcellini e Kieckbusch (2006), os modelos de referências para o Processo de Desenvolvimento de Produto (PDP) podem auxiliar as empresas a visualizarem como e quando os fornecedores poderão ser envolvidos no PDP.

Diante disso, Rosenfeld et al. (2006) consideram que o fator primordial no PDP é a gestão ser conduzida com um fluxo de informações e decisões entre as áreas funcionais de administração em uma empresa de forma compartilhada e integrada. Segundo os mesmos autores, a integração com todos os processos e funções, recebendo e fornecendo informações e compartilhando conhecimentos e atividade são a chave do sucesso.

\subsection{Práticas de gestão aplicadas ao desenvolvimento do produto e processo}

A área de administração da produção e operações é a área envolvida na elaboração de um produto ou serviço, mas não é a única. O planejamento da área é de suma importância e, segundo Slack, Chambers e Johnston (2009, p. 32), entre os diversos aspectos envolvidos, destaca-se: Estrutura de Produto que pode ser definida como um diagrama que identifica e descreve os componentes de um produto final. Conforme Corrêa, Gianesi e Caon (2001), a forma como as estruturas de produto são definidas, além obviamente das características inerentes ao produto em questão, determina a quantidade de níveis e de componentes por nível que as estruturas apresentarão; Roteiro de Produção que determina o melhor método de produção das peças, dos subconjuntos e das montagens dos vários produtos acabados que a fábrica produz. De acordo com Arnold (2012), o controle da atividade de produção necessita dessa informação, a fim de estabelecer prioridades adequadas e responder às questões sobre entregas, reduções e sobre status dos pedidos, e a Cronometragem, que é de grande importância ao controle da produção, baseia-se em conhecimento do tempo necessário para cada tarefa e para cada operação. Segundo Leme (1974, p. 23), a noção de tempos cronometrados, de acordo com a designação clássica, está associada a dois conceitos básicos: o método de execução do trabalho e o tempo padrão.

Nas projeções do desenvolvimento de um produto e de seu processo, deve haver o envolvimento de profissionais das áreas funcionais da empresa, como marketing, produção e operações, finanças, gestão de humanos, etc. O projeto do produto e processo vêm recebendo 
destaque, ao longo dos anos, por exigir uma integração sincronizada, alinhada e constante de toda a empresa. Para sua execução, é necessária a formação de equipes e líderes.

De acordo com Hislop et al. (2000) e Katzenbach e Smith (1995), equipes são constituídas, quando profissionais de diferentes especialidades trabalham próximos e intensivamente no projeto, interagindo durante determinado período de tempo e se responsabilizando mutuamente pelos resultados que produzem.

Clark e Fujimoto (1991) e Sobek II, Ward e Liker (1999) defendem que o líder assume o controle do cronograma do projeto, das principais especificações técnicas e das metas de custo, porém a razão não é a centralização total dessas decisões, mas a responsabilidade de alguém dentro da equipe em relação aos aspectos fundamentais do projeto. Para Clark e Fujimoto (1991), os líderes de projeto possuem determinadas habilidades, o conhecimento das estruturas e dos sistemas da empresa para dar suporte às equipes de desenvolvimento de produtos. Os líderes se comunicam de forma extensiva, influenciando todas as áreas funcionais para viabilizar o desenvolvimento integrado. Cusumano (2000) destaca também que o líder faz o controle do tempo, o compartilhamento de uma visão clara sobre o projeto e suas metas, a responsabilidade de todos e autonomia, a criação de uma linguagem comum à comunicação.

Outro fator importante ao desenvolvimento de um produto e seu processo são os meios de comunicação que propiciam o fluxo e a qualidade na transmissão e entendimento das informações, tornando possível a integração dos membros das equipes de projeto e a execução e coordenação de tarefas simultâneas. Segundo a abordagem dos autores Clark e Fujimoto (1991) e Leenders, Engelen e Kratzer (2003), o fluxo das informações requer meios de comunicação que devem incluir tanto os contatos formais como reuniões periódicas, quanto os contatos informais, realizados por meio de redes de relacionamento pessoal.

A performance do desenvolvimento do produto, resultante da sua organização e gerenciamento, em paralelo à estratégia mercadológica da empresa, é considerada, juntamente com outros fatores, o aspecto determinante da competitividade (CLARK; FUJIMOTO, 1991).

A qualidade é outro fator importante do projeto do produto, porém não será satisfatória se a equipe de projeto conviver com barreiras às mudanças. Conforme Clark e Wheelwright (1993), o primeiro passo a ser dado, no início do processo de desenvolvimento de produtos, é a definição de um mapa com os diferentes tipos de projeto de desenvolvimento de produtos da empresa. Segundo os autores, definir esses tipos de projeto gera importantes informações que direcionam as operações e a alocação dos recursos organizacionais para o processo de desenvolvimento de produtos. Esses recursos podem ser a necessidade do treinamento de 
habilidades específicas dos profissionais envolvidos, a necessidade de líderes e da composição de times de desenvolvimento ou ainda os meios de comunicação disponíveis.

As equipes de desenvolvimento de produtos, dado o agrupamento de profissionais detentores de conhecimento e especialidades relativas ao contexto dos projetos, criam ambiente propício à comunicação e, consequentemente, à aprendizagem e à inovação, possibilitando aos profissionais que os constituem somarem os seus conhecimentos em prol do desenvolvimento de um produto (LEENDERS; ENGELEN; KRATZER, 2003; SOBEK II; SONG, 1997).

Segundo Katzenbach e Smith (1995), o desempenho do trabalho das equipes requer sincronismo, cooperação, confiança e coordenação, independentemente do tamanho da equipe, abrindo caminho ao papel dos líderes de projeto e aos meios de comunicação disponíveis para o processo de desenvolvimento integrado de produtos.

Luhmann (2000, p. 103) e Zucker (1986, p. 54) definem a confiança como um conjunto de expectativas compartilhadas por parceiros de interação, como aceitação voluntária e antecipada de um investimento de risco, pela abdicação de mecanismos contratuais explícitos de segurança e de controle contra comportamentos oportunistas, na expectativa de que a outra parte não agirá dessa forma.

Para Marchi, Cassanego Junior e Wittmann (2012), a confiança é um ativo intangível para os componentes da rede, visto que, em tempos atuais, a eficiência dos processos internos e a aprendizagem organizacional tendem a resultar em atuação competitiva e na criação de valores, como maior facilidade de acesso aos fornecedores, redução de custo de estoque e maior facilidade de aquisição de equipamentos e tecnologias.

\section{RESULTADOS E DISCUSSÕES}

\subsection{Práticas de gestão aplicadas no desenvolvimento do produto e processo da escola de samba}

Em relação às práticas de gestão do processo e desenvolvimento do produto, é importante haver o envolvimento de profissionais das demais áreas de gestão nas organizações. É importante que haja compartilhamento de aspectos relacionados à gestão entre a área de Produção e operações e também Marketing, Finanças, Gestão de humanos e seus desdobramentos. Assim, informações sobre gestão foram coletadas para apresentar como isso acontece na gremiação estudada. Tais informações foram coletadas, por meio de pesquisa 
documental no estatuto da escola de samba, nos sites oficiais da Gremiação e entrevistas com $\mathrm{o}$ agente denominado aqui de $\mathrm{M}$.

Em sua apresentação, o entrevistado relatou: atualmente eu sou vice-presidente de projetos especiais, isso no organograma da escola como um todo e, no carnaval, eu sou membro do conselho de carnaval. Além desses cargos, ele informou que: participo desde 1976, passando por várias etapas de componentes de ala até membro da diretoria. Já ocupei a vice-presidência administrativa e vice-presidência de conselho deliberativo.

Com tal relato, pode-se afirmar que o entrevistado está colaborando na escola por 44 anos, podendo-se considerar que tem conhecimento e experiência sobre o negócio tratado.

$\mathrm{Na}$ sequência, considerando os relatos do entrevistado $\mathrm{M}$, estão reunidas as informações sobre as práticas de gestão da produção do produto "Desfile" da escola de samba.

\section{2 Área de MKT: concepção do produto}

A área de Marketing é a responsável por captar informações no mercado para subsidiar a concepção do produto nas organizações. Nessa perspectiva, segundo o entrevistado $\mathrm{M}$, quem tem esse papel formal, conforme mostra o estatuto da gremiação, é o conselho de carnaval. A coordenação acontece pelo Diretor Carnavalesco que tem as atividades de supervisão da equipe de criação, desenvolvimento do enredo da escola para o carnaval, elaboração de pesquisas sobre o tema, sob sua responsabilidade. Apesar de estar formalizado no estatuto, segundo o entrevistado $\mathrm{M}$, todo o movimento para conceber o enredo/tema do carnaval é decidido de forma compartilhada "pela diretoria, membros da escola, carnavalesco e patrocinadores, e esse projeto, na verdade, ele tem vários momentos; essa estrutura é uma maneira como nós operamos, é um grupo de pessoas que trabalham o carnaval da escola. É um formato que eles costumam usar em relação a decisões importantes a serem tomadas.

\section{3 Área produção e operações}

$\mathrm{Na}$ área de produção e operações são realizados os processos de produção e seu planejamento inicia-se pós concepção do produto Desfile definida.

Conforme o entrevistado $\mathrm{M}$, para a produção do produto Desfile, são produzidos alguns subprodutos que são: você tem bateria, você tem fantasia, você tem o samba, você tem o casal de mestre-sala e porta-bandeira, você tem uma comissão de frente, o próprio enredo. 
A partir o enredo, você monta tuas alegorias, tuas fantasias, teu samba. Tudo isso é trabalhado pra você fazer um bom carnaval.

Os trabalhos iniciam-se com a coordenação do Diretor Carnavalesco que tem as atividades de desenvolvimento de croquis das fantasias e coordenação dos projetos para a produção. Pode-se dizer que é o Diretor Carnavalesco o líder de todo processo.

Os processos envolvidos são: Ferragem, carpintaria, escultura, laminação, pintura e ainda existe o processo de pós-produção cenotécnica e testes controlados. Ocorrem a produção de fantasias e adereços, carros alegóricos, criação e preparação dos elementos musicais que são o samba-enredo e a bateria e, por último, criação e preparação das performances e coreografias das alas.

A partir da definição do tema e das fontes de recursos financeiros, inicia-se o processo produtivo nos barracões. Segundo o entrevistado M, "são feitos os desenhos dos figurinos e o carro alegórico é apresentado com planta baixa. Mas depende, tem carnavalesco que usa assim, tem carnavalesco que não usa assim, tem carnavalesco que chega com uma pegada mais hitec, tem outros que fazem na mão, desenham; tem carnavalesco que não desenha e que alguém faz pra ele; cada lugar é de uma forma, cada pessoa é de uma forma".

O processo de produção das alegorias e fantasias ocorre no barracão da escola, na Cidade do Samba e em ateliês situados no centro da cidade, contratados especificamente para essa finalidade, diferente do que acontecia no passado, quando os próprios integrantes das escolas confeccionavam as fantasias. Segundo o entrevistado M: o barracão tem uma estrutura que todas as escolas receberam, barracões bastante similares, isto é, temos espaço físico e estruturação, cada uma faz os seus arranjos.

No caso das quadras, são espaços em que ocorrem as reuniões, os ensaios para o grande desfile, os concursos de samba, festas e ensaios das escolas de samba. Normalmente elas têm um palco, um bar, um espaço para dança e camarotes para a acomodação dos membros da diretoria, convidados e pessoas ilustres. E, segundo o entrevistado M, a quadra, cada uma tem um tipo de utilização. Normalmente a quadra se envolve na questão da produção do carnaval, na disputa do samba enredo e nos ensaios que acontecem. A gente faz ensaio de rua que é o mais próximo do que a gente vai trabalhar no desfile em si. Tem o ensaio técnico na Sapucaí, mas você não leva todas as surpresas que vai levar, não gasta todas as suas, é novidades. Você vai pra lá treinar no campo de jogo, fazer um trabalho a partir daí. 
Em relação às compras dos recursos materiais e patrimoniais, que são os recursos físicos de produção utilizados, o entrevistado $\mathrm{M}$ relatou: essa coisa de equipamentos, depende, tem coisas que você terceiriza, tem coisas que você tem no barracão, tem coisas que você usa em diferentes fases. Em relação às compras de matéria-prima, elas são realizadas em grande quantidade com vista à redução dos custos finais e com fornecedores fixos e fornecedores esporádicos e assim relatou o entrevistado: a gente vai atrás do que todo mundo tem que fazer, buscar bons preços, bons prazos e bons produtos.

No caso do enredo, a aquisição pode acontecer com fornecedores externo ou interno. O entrevistado M relatou que: o enredo, em si, pode ser apresentado por qualquer pessoa, como eu falei, pode ser um enredo patrocinado ou não, ele vai ser analisado e vai se ver se ele é interessante para a escola ou não.

No processo de produção do produto final, o "Desfile", existem as alas da comunidade e a comercial. As fantasias das alas da comunidade são responsabilidade da agremiação, produzidas no próprio barracão e doadas aos seus integrantes, respeitando critérios próprios. Elas são confeccionadas nos galpões da Cidade do Samba ou em ateliês e as das alas comerciais em ateliês ou nas residências dos responsáveis pelas alas.

Terminado o desfile, entrega do produto que envolve a razão e a emoção na avenida, a equipe reinicia tudo, com nova concepção do produto, readequação dos projetos do produto e do processo para o próximo ano. Há um desmanche de todos os subprodutos e reaproveitamento de tudo que foi utilizado para o próximo desfile de carnaval.

\subsection{Cronograma e atividades necessários para a produção do produto escola de samba projetado}

Em relação ao cronograma, o entrevistado $\mathrm{M}$ relatou: você tem todo um cronograma de trabalho, você tem toda uma evolução de trabalho. O cronograma de atividades é a gente que estabelece e distribui as atividades ao longo do ano para se produzir o desfile. Esse cronograma se divide em quatro partes: produção de fantasias e adereços, produção de carros alegóricos, criação e preparação dos elementos musicais, que são o samba-enredo e a bateria e, por último, criação e preparação das performances, coreografias das alas.

Os protótipos das fantasias que são produzidas pelas costureiras do barracão são elaborados, ao longo dos meses de maio e junho, juntamente com os projetos dos carros alegóricos. Em agosto, inicia-se o processo de confecção das fantasias, cuja responsabilidade passa a ser dos chefes das alas. 
Os carros alegóricos ficam sob a responsabilidade do Diretor de Barracão. Inicialmente, entre os meses de março e maio, é feito o desmonte dos carros, selecionando o material a ser reaproveitado. Em julho, inicia-se o processo de montagem das novas alegorias, envolvendo diferentes profissionais que, em grande parte, são contratados em regime temporário. Desde o início da montagem até o produto final, seguem-se várias etapas: instalação de ferragens, montagem de carpintaria, criação das esculturas, pintura, adereçamento, instalações elétricas, de efeitos especiais e mecânicos.

Junto ao desenrolar dos processos, são realizadas as análises e controle de custos de tempo, quantidade de recursos, de desempenho, o tempo todo. Sobre isso o entrevistado M relatou que: é feito por todos. Tudo que está sendo realizado tem que ser feito o mais correto possível, porque, segundo o entrevistado, na produção do Desfile: não têm recall, se tiver errado vai errado...não vai adiar o dia...tocou a campainha pra entrar e não entrou cê começa perde o carnaval.

\section{5 Área de finanças}

Toda a produção do produto "Desfile" da escola de samba segue um planejamento que abrange a previsão orçamentária e o patrocínio. Assim, os recursos financeiros, conforme o entrevistado M: vem de várias fontes como das cotas da TV; ela vem da liga das escolas de samba; vinha antigamente, quando tinha prefeito decente da prefeitura e do governo do estado também já veio; vem de projetos incentivados e em algumas escolas vêm de patrocínio de enredos patrocinados. A captação de patrocínio se inicia logo após o Carnaval e se estende até meados de julho.

As outras fontes identificadas dos recursos financeiros, são:

- Realização de shows e eventos particulares;

- A venda de produtos com a marca da escola, tais como: bonés e camisetas;

- A realização de eventos na quadra da escola;

- A venda de CDs com sambas-enredos da escola;

- A venda de fantasias para a participação no desfile e patrocínios de empresas parceiras.

Além disso, a escola, bem como todas as escolas de samba pertencentes à Liga das Escolas de Samba (LIESA), têm direito à participação nos recursos financeiros obtidos com:

- Venda dos ingressos do sambódromo; 
- Direitos de imagem dos desfiles, com a venda de material audiovisual realizada pela Liga e toda a comercialização de produtos ou serviços concernentes ao carnaval realizado pela Liesa.

- Prêmios em dinheiro concedidos pela Liesa, de acordo com suas classificações no carnaval;

- Subsídio financeiro concedido pela prefeitura para auxiliar na realização do carnaval;

- Também são realizadas parcerias com empresas patrocinadoras interessadas na divulgação de suas marcas.

\section{5 Área de Gestão de Pessoas: equipe de trabalho}

Em relação aos trabalhos, são realizados numa maioria em equipe de colaboradores contratados e terceirizados. A seleção de colaboradores é feita da seguinte forma, conforme o entrevistado M: hoje, em termos formais, tá tendo muito a utilização do MEI, tem as pessoas que constroem uma história e a gente sabe que são boas e chama e ficam e continuam trabalhando. Essas coisas vão acontecendo.

Como foi mencionado, existem colaboradores Fixos e Terceirizados e ainda os líderes de equipes. Os colaboradores que participam do processo de produção, no relato do entrevistado M: hoje é algo profissional. O primeiro colaborador contratado é o carnavalesco que tem como responsabilidade a concepção do produto desfile. Além disso, ele é responsável pela coordenação de equipes que trabalham com as etapas de produção de fantasias e carros alegóricos. Fica sob a responsabilidade do carnavalesco a escolha dos profissionais especializados, para a equipe de produção, que é formada por: ferreiros, marceneiros, carpinteiros, escultores, eletricistas, iluminadores, desenhistas, cenógrafos, figurinistas, aderecistas, costureiras, bordadeiras, vidraceiros, pintores, ceramistas e decoradores.

Além do carnavalesco, existem os chefes de alas que não só contratam costureiras e aderecistas, para a confecção das fantasias e adereços, como também assumem a tarefa de comercialização das fantasias.

$\mathrm{O}$ entrevistado $\mathrm{M}$ relatou para finalizar que: ainda existem aqueles colaboradores voluntários que independe de ganhar dinheiro ou não, eles querem estar na produção do desfile, tem uma paixão louca ... mas a questão é você realmente trabalhar com quem você acredita e confia. 


\subsection{Comunicação e nível de confiança existente entre os envolvidos no processo.}

A comunicação entre os colaboradores, para ocorrer a troca de informações e coordenação entre as equipes envolvidas no processo de produção do produto desfile da escola de samba, é feita no momento da distribuição dos trabalhos, segundo o entrevistado M e depois: cada um em sua área...não tem assim uma grande reunião pra definir não.

A troca de conhecimento, dentro das escolas de samba, segundo o entrevistado M: elas são de todas as formas, uma reunião é necessária quando acontece a identificação de alguma coisa feita desalinhada, mas acontece informal, é sempre no sentido de que se trabalha contra o tempo e você tem que dar conta.

Por esses resultados, pode-se afirmar que há relações de confiança entre os integrantes no processo de produção. O indicativo disso é a informalidade na comunicação e troca de conhecimentos que é feita informalmente, por meio de redes sociais, entre todos os colaboradores, pode gerar alinhamento e comprometimento que pode resultar no êxito da premiação.

\section{CONSIDERAÇÕES FINAIS}

Pode-se concluir que foi possível conhecer as práticas de gestão aplicadas ao desenvolvimento do produto Escola e Samba, "Desfile", do grupo especial do Rio de Janeiro.

$\mathrm{Na}$ área de marketing, a concepção e definição do tema/enredo é feita após a negociação entre os possíveis patrocinadores e o diretor carnavalesco. Se não conseguir o patrocínio, os membros da diretoria da escola de samba definem o conceito por eles mesmos.

$\mathrm{Na}$ área de produção, após a definição do tema/enredo, que é considerado, nesta pesquisa, como a base para a produção do produto e das fontes de recursos financeiros, é que se inicia o processo produtivo nos barracões.

$\mathrm{Na}$ área de gestão de pessoas, as formas mais comuns de trabalhos desenvolvidos pelos colaboradores da escola de samba são em equipe, mas existe algum individual. Existe uma profissionalização entre todos.

$\mathrm{Na}$ área financeira, os recursos financeiros vêm das cotas da TV; LIESA; da prefeitura e do governo do estado; projetos incentivados e de patrocínio de enredos. A captação de patrocínio se inicia logo após o Carnaval e se estende até meados de julho. Outras fontes são pela realização de shows e eventos particulares; a venda de produtos com a marca da escola, tais como: bonés e camisetas; a realização de eventos na quadra da escola; a venda 
de CDs com sambas-enredo da escola; a venda de fantasias para a participação no desfile e patrocínios de empresas parceiras. Os trabalhos seguem um rígido cronograma.

Em relação à comunicação, o fluxo de informações e a troca de conhecimento acontecem para as equipes e nas equipes entre os envolvidos e continuamente de modo informal por meio de redes sociais.

Pode se dizer que há indicativos de alinhamento, integração nas decisões e confiança.

\section{REFERÊNCIAS}

ARNOLD, J. R. T. Administração de materiais: uma introdução. Tradução Celso Rimoli e Lenita R. Esteves. 10. reimpr. São Paulo: Atlas, 2012.

BARCZAK, G.; GRIFFIN, A.; KAHN, K. B. Perspectiva: tendências e impulsionadores do sucesso nas práticas de NPD: resultados do estudo de práticas recomendadas de 2003 PDMA. Journal of Product Innovation Management, New York, v. 26, n. 1, p. 3-23, 2009.

BARDIN, L. Análise de conteúdo. Lisboa: Edições 70, 2001.

BAXTER, M. Product design: a practical guide to systematic methods of new product development. Brunel: Chapman \& Hall, 2002. 308 p.

BAXTER, M. Projeto de produto: guia prático para o desenvolvimento de novos produtos. São Paulo: Blucher, 1998.

BERNHOEFT, R. Escola de samba é referência de gestão no Brasil. $O$ portal da Administração. 6 fev. 2013. Disponível em: http://www.administradores.com.br/artigos/ negocios/escola-de-samba-e-referencia-de-gestao-no-brasil/68678/. Acesso em: 23 mar. 2015.

BERTO, R. M. V. S.; NAKANO, D. N. Metodologia da pesquisa e a Engenharia de produção. In: ENCONTRO NACIONAL DE ENGENHARIA DE PRODUÇÃ̃O - ENEGEP, 18; INTERNATIONAL CONGRESS OF INDUSTRIAL ENGINEERING - ICIE, 4., 1998, Niterói. Anais [...] Niterói: ABEPRO, 1998.

BIDAULT, F.; DESPRES, C.; BUTLER, C. New Product development and Early Supplier Involvement ESI): the drivers of ESI adoption. In: THE PRODUCT DEVELOPMENT MANAGEMENT ASSOCIATION INTERNATIONAL CONFERENCE, 1996, Orlando. Proceedings [...] Orlando: 1996.

BRAGA, G. H. Turismo brasileiro comemora números do Carnaval. Brasília: Ministério do Turismo, 2015. Disponível em: http://www.turismo.gov.br/turismo/noticias/todas_ noticias/20150223_2.html./. Acesso em: 31 mar. 2015.

BRASIL. Ministério do Turismo. Assessoria de Comunicação Social (ASCOM). Brasil se prepara para o maior carnaval da história. Disponível em: http://www.turismo.gov.br/ turismo/noticias/todas_noticias/20140225-2.html//. Acesso em: 31 mar. 2019. 
CLARK, K. B.; FUJIMOTO, T. Product development performance: strategy, organization and management in the world auto industry. Boston: Harvard Business School Press, 1991.

CLARK, K. B.; WHEELWRIGHT, S. C. Managing new product and process development: text and cases. Boston: Harvard Business School Press, 1993.

CLAUSING, D. P. Total quality development. Mechanical Engineering, New York, v. 116, n. 3, p. 94-96, 1994.

CORRÊA, H. L.; GIANESI, I. G. N.; CAON, M. Planejamento, programação e controle da produção. São Paulo: Atlas, 2001. v. 1.

CUSUMANO, M. A. Making large teams work like small teams: product development at microsoft. In: JÜRGENS, U. (ed.). New product development and production networks. Berlin: Springer-Verlag, 2000.

FERNANDES, R. Diretor de carnaval do GRES Unidos de Vila Isabel. Entrevista concedida em 12 abr. 2009. Rio de Janeiro, 2009.

FUJIMOTO, T. Shortening lead time through early problem-solving: a new round of capability building competition in the auto industry. In: JÜRGENS, U. (ed.). New product development and production networks. Berlin: Springer-Verlag, 2000.

GOBE, A. C. Gerência de produtos. São Paulo: Saraiva Educação, 2004.

HALE, A.; KIRWAN, B.; KJELLÉN, U. Safe by design: where are we now? Safety Science, Amsterdam, v. 45, n. 1/2, p. 305-327, 2007.

HISLOP, D. et al. Innovation processes and the management of Knowledge. 2000. Disponível em: http://bprc.warwick. ac.uk/km063.pdf. Acesso em: 22 jan. 2021.

JOHANN, S. L. O modelo brasileiro de gestão organizacional. São Leopoldo: UNISINOS, 1996.

KATZENBACH, J. R.; SMITH, D. K. The discipline of teams. In: CLARK, K. B.; WHEELWRIGHT, S. C. (ed.). The product development challenge: competing through speed, quality and creativity. Boston: Harvard Business School Press, 1995.

LEENDERS, R. T. H. A. J.; ENGELEN, J. M. L.; KRATZER, J. Virtuality, communication and new product team creativity: a social network perspective. Journal of Engineering and Technology Management, Amsterdam, v. 20, n. 1/2, p. 69-92, 2003.

LEME, R. A. S. Controles na produção.2. ed. São Paulo: Pioneira, 1974.

LOPES, C. A.; MALAIA, M. C. B. T.; VINHAIS, J. C. Administração em Escolas de Samba: os bastidores do sucesso do Carnaval carioca. Disponível em: http://www.aedb.br/ seget/arquivos/artigos09/401_401Administracao\%20em $\% 20$ escolas $\% 20 \mathrm{de} \% 20$ samba $\% 20 \% 2$ 0os $\% 20$ bastidores $\% 20 \mathrm{do} \% 20$ sucesso $\% 20 \mathrm{do} \% 20$ Carnaval\%20carioca.pdf $/ /$. Acesso em: 01 abr. 2015. 
LUHMANN, N. Familiarity, confidence, trust: problems and alternatives. Trust: Making and Breaking Cooperative Relations, Berlin, v. 6, p. 94-107, 2000.

MARCHI, J. J.; CASSANEGO JUNIOR, P.; WITTMANN, M. L. Troca e criação de valor: possibilidades competitivas advindas da estratégia de redes. Revista de Administração, São Paulo, v. 47, n. 2, p. 180-196, 2012.

PONTES, M. C. A gestão do samba. HSM Management, São Paulo, v. 92, p. 59-64, 2012.

ROtondaro, G. R.; Miguel, P. A. C.; GOMES, L. A. V. Projeto do produto e do processo. São Paulo: Atlas, 2010.

ROZENFELD, H. et al. Gestão de desenvolvimento de produtos: uma referência para a melhoria do processo. São Paulo: Saraiva, 2006.

SANTOS, A. C.; FORCELLINI, F. A. Avaliação do envolvimento do fornecedor no processo de desenvolvimento de produto (PDP) com base em um modelo de referência para a indústria de alimentos. Produto Gestão e Desenvolvimento, Apucarana, v. 3, n. 1, p. 49-53, 2005.

SANTOS, A. C.; FORCELLINI, F. A. Effects of product development decision-making process on the supply chain. Product Management and Development, Apucarana, v. 7, n. 1, p. 39-46, 2009.

SANTOS, J. M. Estratégia de gestão para o sucesso: o caso do Grêmio Recreativo Cultural Social Escola de Samba Vai-Vai. Disponível em: http://www.convibra.com.br/upload/ paper/adm/adm_2351.pdf//. Acesso em: 01 abr. 2015.

SCALICE, R.; NEUMANN, C. Projeto de fábrica e layout. Rio de Janeiro: Elsevier, 2015.

SILVA, L. A. M. Um olhar administrativo no mundo do samba a partir da gestão de projetos. In: ENANGRAD, 24., 2013, Florianopolis. Anais [...]. Florianópolis: Uni-Facef, 2013.

SLACK, N. et al. Administração da produção. São Paulo: Atlas, 2009.

SOBEK II, D. K.; WARD, A.; LIKER, J. K. Toyota's principles of set-based concurrent engineering. Sloan Management Review, Cambridge, v. 40, n. 2, p. 67-83, 1999.

SOHLENIUS, G. Concurrent engineering. Annals of the CIRP, Paris, v. 41, n. 2, p. 645-655, 1992.

SONG, M.; MONTOYA-WEISS, M. M.; SCHMIDT, J. B. Antecedents and consequences of cross functional cooperation: a comparison of $\mathrm{R} \& \mathrm{D}$, manufacturing, and marketing perspectives. Journal of Product Innovation Management, New York, v. 14, n. 1, p. 35-47, 1997.

STARK, J. Product lifecycle management: 21st century paradigm for product realization. London: Springer, 2006. 411 p. 
TRIVINOS, A. N. S. Três enfoques na pesquisa em ciências sociais: o positivismo, a fenomenologia e o marxismo. In: Introdução à pesquisa em ciências sociais: a pesquisa qualitativa em educação. São Paulo: Atlas, 1987. cap. 2, p. 30-79.

WOMACK, J. P.; JONES, D. T.; ROOS, D. A máquina que mudou o mundo. 12. ed. Tradução Ivo Korytwki. Rio de Janeiro: Campus, 1992. p. 347.

ZUCKER, L. G. Production of trust: institutional sources of economic structure 1840-1920. In: STAW, B. M.; CUMMINGS, B. M. Research in organization behavior. Greenwich: JAI, 1986. p. 53-111.

\section{Como Referenciar este Artigo, conforme ABNT:}

MENDONÇA, M. C. A; MACHADO, B. J. L; PEIXOTO, M. G. M. Práticas de Gestão da Produção do Produto Escola de Samba: O Show Turístico do Carnaval Carioca. Rev. FSA, Teresina, v.19, n. 1, art. 3, p. 39-57, jan. 2022.

\begin{tabular}{|l|c|c|c|}
\hline \multicolumn{1}{|c|}{ Contribuição dos Autores } & $\begin{array}{c}\text { M. C. A. } \\
\text { Mendonça }\end{array}$ & $\begin{array}{c}\text { B. J. L. } \\
\text { Machado }\end{array}$ & $\begin{array}{c}\text { M. G. M. } \\
\text { Peixoto }\end{array}$ \\
\hline 1) concepção e planejamento. & $\mathrm{X}$ & $\mathrm{X}$ & $\mathrm{X}$ \\
\hline 2) análise e interpretação dos dados. & $\mathrm{X}$ & $\mathrm{X}$ & $\mathrm{X}$ \\
\hline 3) elaboração do rascunho ou na revisão crítica do conteúdo. & $\mathrm{X}$ & $\mathrm{X}$ & $\mathrm{X}$ \\
\hline 4) participação na aprovação da versão final do manuscrito. & $\mathrm{X}$ & $\mathrm{X}$ & $\mathrm{X}$ \\
\hline
\end{tabular}

